\title{
Electron Irradiation Effects on the Optical and Electrical Properties of $\mathrm{ZnO} / \mathrm{Ag} / \mathrm{SnO}_{2}$ Thin Films
}

\author{
Yu-Sung Kim', Jin-Young Choi ${ }^{2}$, Yun-je park², Su-Hyeon $\mathrm{Choe}^{2}$, \\ Byung-Chul Cha', Young-Min Kong ${ }^{2}$, and Daeil Kim ${ }^{2}$,* \\ ${ }^{1}$ Advanced Forming Processes R\&D Group, Korea Institute of Industrial Technology, Ulsan 44413, Republic of Korea \\ ${ }^{2}$ School of Materials Science and Engineering, University of Ulsan, Ulsan 44776, Republic of Korea
}

\begin{abstract}
Transparent conductive $\mathrm{ZnO} 50 \mathrm{~nm} / \mathrm{Ag} 10 \mathrm{~nm} / \mathrm{SnO}_{2} 50 \mathrm{~nm}$ (ZAS) tri-layer films were deposited on glass substrates by magnetron sputtering, and then the surface was subjected to intense electron beam irradiation to investigate the effects of electron irradiation on the structural, optical, and electrical properties of the films. After deposition, the ZAS thin films were electron-irradiated for 10 minutes, with varying electron incident energies of 300,600, and $900 \mathrm{eV}$. The films that were electron irradiated at $900 \mathrm{eV}$ showed higher optical transmittance of $83.6 \%$ in the visible wavelength region, and lower resistivity, of $4.75 \times 10^{-5} \Omega \mathrm{cm}$, than the other films. From the observed electrical properties and optical band gap, it was concluded that the optical band gap increased with the incident electron energy up to $600 \mathrm{eV}$. The optical band gap increased from 4.12 to $4.23 \mathrm{eV}$, with carrier density increasing from 7.09 to $8.55 \times 10^{21} \mathrm{~cm}^{-3}$. However, the film electron irradiated at $900 \mathrm{eV}$ showed a decrease in optical band gap energy of $4.16 \mathrm{eV}$ due to the decreased carrier density of $8.25 \times 10^{21} \mathrm{~cm}^{-3}$. The figure of merit revealed that the ZAS thin films electron-irradiated at $900 \mathrm{eV}$ had higher optical and electrical performance than the other films prepared in this study.
\end{abstract}

(Received September 30, 2019; Accepted December 23, 2019)

Keywords: $\mathrm{ZnO}, \mathrm{Ag}, \mathrm{SnO}_{2}$, magnetron sputtering, figure of merit.

\section{INTRODUCTION}

The increasing use of transparent conducting oxide (TCO) thin films for various display devices is stimulating the development of inexpensive TCO films that simultaneously have high optical transmittance and low resistivity [1]. Recently, gallium or aluminum doped zinc oxide $(\mathrm{ZnO})$ films have attracted attention, because of their appropriate visible transmittance, low resistivity, and relatively low cost compared to conventional Sn-doped $\operatorname{In}_{2} \mathrm{O}_{3}$ (ITO) thin films [2].

It is well known that most metal-doped $\mathrm{ZnO}$ films require high substrate temperatures $\left(\geq 300^{\circ} \mathrm{C}\right)$ to increase the electrical conductivity and visible transmittance [3]. However, for flexible, durable, and lightweight display systems, high substrate temperatures are undesirable, because of the low thermal resistivity of plastic substrates.

- 김유성·차병철: 연구원, 최진영·박윤제·최수현: 석사과정, 김대일·공영민: 교수 *Corresponding Author: Daeil Kim

[Tel: +82-52-712-8066, E-mail: dkim84@ulsan.ac.kr]

Copyright (C) The Korean Institute of Metals and Materials
Accordingly, many studies [4-6] have focused on room temperature technologies that can ensure both high optical transmittance and low resistivity in TCO films, without deformation of the flexible polymer substrates.

In this study, we deposited $\mathrm{ZnO} 50 \mathrm{~nm} / \mathrm{Ag} 10 \mathrm{~nm} / \mathrm{SnO}_{2} 50$ $\mathrm{nm} /$ (ZAS) tri-layer films using radio frequency (RF) and direct current (DC) magnetron sputtering. Then we electron beam-irradiated the films to investigate the effect of electron irradiation on their electrical and optical properties, using $\mathrm{x}$ ray diffractometer (XRD), atomic force microscopy (AFM), and UV-visible (UV-Vis) spectrophotometry, respectively.

\section{EXPERIMENTAL PROCEDURES}

Figure 1 shows the RF and DC magnetron sputter system with an electron irradiation (INFO-RFE-60G, Infovion) that was used to deposit the $\mathrm{ZnO} 50 \mathrm{~nm} / \mathrm{Ag} 10 \mathrm{~nm} / \mathrm{SnO}_{2} 50 \mathrm{~nm}$ (ZAS) tri-layer films at room temperature. We used slide glass (size: $25 \times 25 \mathrm{~mm}$, thickness: $1.0 \mathrm{~mm}$, Corning 2948) as the substrate. The distance from the target to the substrate 


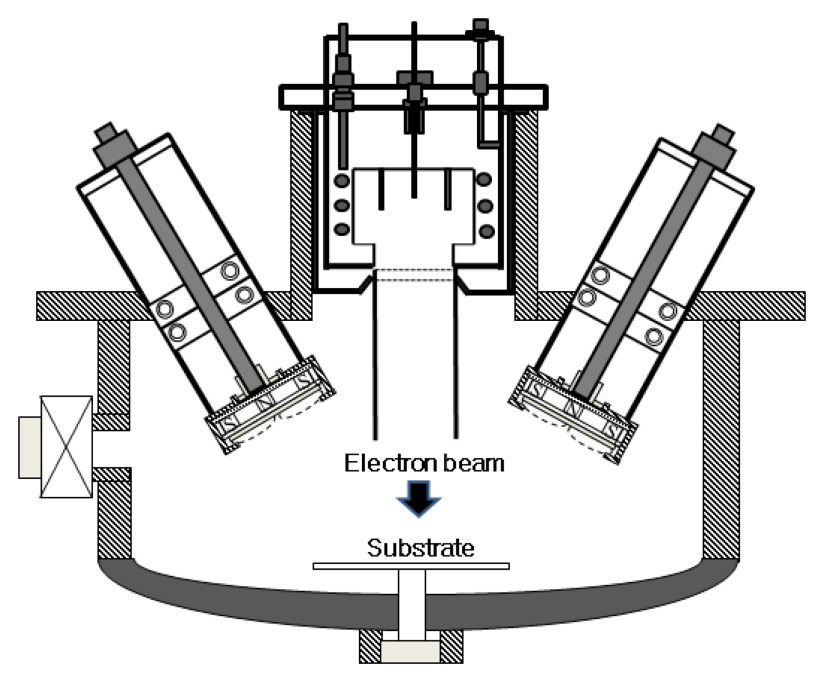

Fig. 1. Schematic diagram of the RF and DC magnetron sputtering system with an electron beam source.

was kept at $60 \mathrm{~mm}$.

Prior to deposition, we evacuated the chamber to $5.0 \times 10^{-7}$ Torr, and then injected inert argon (Ar) gas at a constant flow rate of $10 \mathrm{sccm}$ to maintain a deposition pressure at $1.0 \times$ $10^{-3}$ Torr for all depositions. During deposition, both the $\mathrm{ZnO}$ and $\mathrm{SnO}_{2}$ targets were biased $\mathrm{RF} 2.5 \mathrm{~W} / \mathrm{cm}^{2}$, while the $\mathrm{Ag}$ target was DC $2.0 \mathrm{~W} / \mathrm{cm}^{2}$. For ZAS films deposited at room temperature, the substrate temperature was increased from 30 to $60^{\circ} \mathrm{C}$.

After deposition, we biased an electrical power of $200 \mathrm{~W}$ on an RF $(13.56 \mathrm{MHz})$ antenna in an electron beam source and varied the electron irradiation energy at 300,600, and $900 \mathrm{eV}$ in a low vacuum of $1 \times 10^{-5}$ Torr (Ar atmosphere).

We investigated the crystallinity of the ZAS thin films using XRD (X'pert PRO MRD, Philips) with $\mathrm{Cu}-\mathrm{K} \alpha$

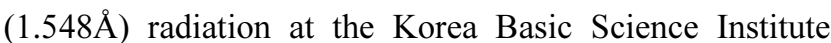
(KBSI), Daegu Center. We measured the optical transmittance and electrical resistivity by UV-visible spectrophotometer (Carry 100 Cone, Varian) in the range from 380-780 nm, and Hall Effect measurements (HMS3000, Ecopia) in the Van der Pauw configuration. The bare slide glass had an optical transmittance of $90 \%$ in the visible wavelength region. In addition, we investigated the influence of electron irradiation on the surface roughness of the films using AFM (scan area: $2 \times 2 \mu \mathrm{m}$, XE-100, Park Systems).

\section{RESULTS AND DISCUSSION}

Figure 2 shows the XRD patterns observed from the ZAS tri-layer films as a function of electron irradiation energy. All of the XRD plots exhibited diffraction peaks of the Ag and $\mathrm{ZnO}$ planes regardless of the electron irradiation energy, while the characteristic diffraction peak for crystalline $\mathrm{SnO}_{2}$ did not appear for the low electron energy condition $(\leq 600$ $\mathrm{eV})$. The films electron irradiated at $900 \mathrm{eV}$ exhibited the diffraction peaks of $\mathrm{SnO}_{2}$ (211), $\mathrm{ZnO}$ (002), (103) and $\mathrm{Ag}$ (111), (200), respectively. Recently R. L. Orimi et al. [7] reported on the growth mode of polycrystalline $\mathrm{SnO}_{2}$ thin films deposited on glass substrate at $450{ }^{\circ} \mathrm{C}$ by chemical spray pyrolysis technique. However, it is supposed that the crystal growth of $\mathrm{SnO}_{2}$ film by electron irradiation commenced at $900 \mathrm{eV}$.

Table 1 shows the grain size (D) of the $\mathrm{ZnO}$ (002) and Ag (111) planes, considered by the Scherrer formula for each film:

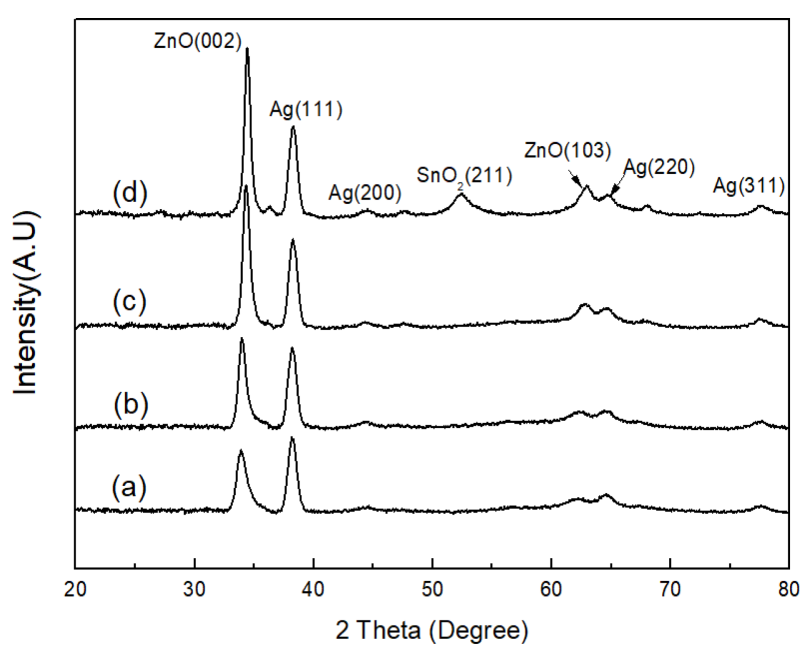

Fig. 2. The XRD pattern of the ZAS tri-layer films electron irradiated at different incident energy. (a) As deposition, (b) $300 \mathrm{eV}$, (c) $600 \mathrm{eV}$, and (d) $900 \mathrm{eV}$.

Table 1. Grain size (D) of $\mathrm{ZnO}$ and $\mathrm{Ag}$ thin films as a function of electron irradiated energy.

\begin{tabular}{ccc}
\hline $\begin{array}{c}\text { Electron energy } \\
(\mathrm{eV})\end{array}$ & $\begin{array}{c}\mathrm{ZnO}(002) \\
\text { Size }(\mathrm{nm})\end{array}$ & $\begin{array}{c}\mathrm{Ag}(111) \\
\text { Size }(\mathrm{nm})\end{array}$ \\
\hline As deposition & 9.6 & 9.9 \\
\hline 300 & 12.4 & 9.9 \\
\hline 600 & 13.4 & 10.0 \\
\hline 900 & 14.5 & 10.2 \\
\hline
\end{tabular}


Table 2. The figure of merit of ZAS films electron irradiated at different energies.

\begin{tabular}{cccc}
\hline $\begin{array}{c}\text { Irradiation } \\
\text { Energy } \\
(\mathrm{eV})\end{array}$ & $\begin{array}{c}\text { Sheet } \\
\text { resistance } \\
(\Omega / \square)\end{array}$ & $\begin{array}{c}\text { Visible } \\
\text { transmittance } \\
(\%)\end{array}$ & $\begin{array}{c}\text { Figure of } \\
\text { merit } \\
\left(10^{-2} \Omega^{-1}\right)\end{array}$ \\
\hline As deposition & 11.0 & 80.8 & 1.06 \\
\hline 300 & 5.6 & 81.1 & 2.44 \\
\hline 600 & 4.2 & 81.3 & 2.97 \\
\hline 900 & 4.3 & 83.6 & 3.86 \\
\hline
\end{tabular}

(a)

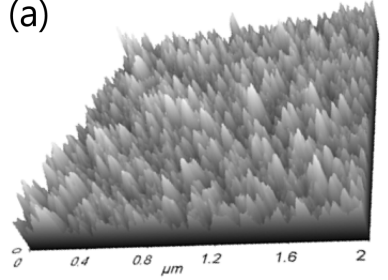

(c)

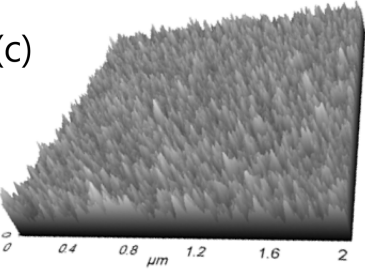

(b)

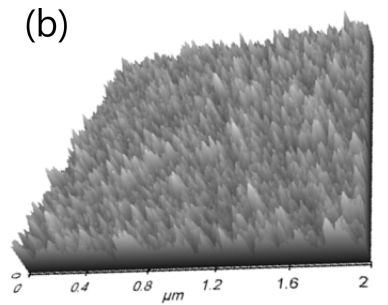

(d)

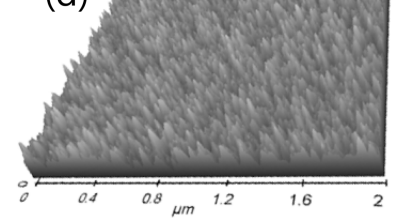

Fig. 3. Surface morphology and RMS roughness of the ZAS trilayer films electron irradiated at different energy. (a) As deposition, RMS roughness; $0.75 \mathrm{~nm}$, (b) $300 \mathrm{eV}$, RMS roughness; $0.73 \mathrm{~nm}$, (c) $600 \mathrm{eV}$, RMS roughness; $0.62 \mathrm{~nm}$, (d) $900 \mathrm{eV}$, RMS roughness; $0.51 \mathrm{~nm}$.

$$
\mathrm{D}=0.9 \lambda / B \cos \theta
$$

where $\mathrm{D}$ is the grain size, $\lambda$ is the $\mathrm{X}$-ray radiation wavelength, $B$ is the full-width at half-maximum (FWHM) of the diffraction peak, and $\theta$ is the Bragg angle of the diffraction peak [8]. Table 2 shows that the crystallite size in the $\mathrm{ZnO}$ and $\mathrm{Ag}$ interlayers increased with electron irradiation energy.

Figure 3 shows the AFM images of the as-deposited and the electron beam-irradiated ZAS films. While the asdeposited films showed an RMS roughness of $0.75 \mathrm{~nm}$, the films electron-irradiated at $900 \mathrm{eV}$ showed the lowest RMS roughness of $0.51 \mathrm{~nm}$.

Figure 4 shows the optical transmittance of the ZAS films in the visible wavelength region. The as-deposited films showed an average visible transmittance of $80.8 \%$, while the films electron-irradiated at $900 \mathrm{eV}$ showed an increased average visible transmittance of $83.6 \%$.

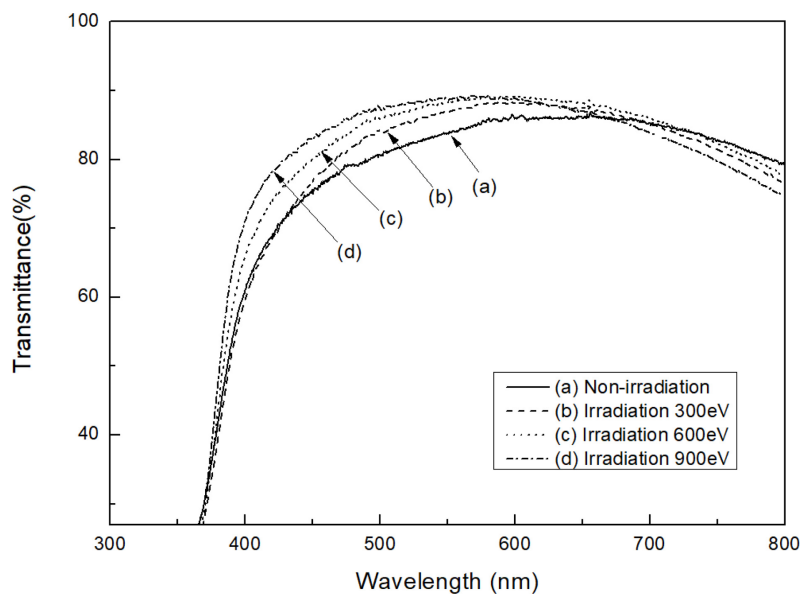

Fig. 4. The visible transmittance of the ZAS tri-layer films electron irradiated at different energy.

H. N. Cui [9] reported that surface scattering can cause a reduction in the optical transmittance of TCO thin films, with the optical scattering being caused either by surface microroughness, or by scattering at the film grain boundaries. From the XRD and AFM observation, the increased visible transmittance of the ZAS film is attributed to a flatter surface and larger grain size, resulting from the post-deposition electron irradiation.

Table 2 shows the figure of merit (FOM) as a function of electron irradiation energy. The FOM is an important index for evaluating the opto-electrical performance of TCO films. The FOM is defined as

$$
\mathrm{FOM}=\mathrm{T}^{10} / \mathrm{R}_{\mathrm{sh}}
$$

where $T$ is the average visible transmittance and $R_{\text {sh }}$ is the sheet resistance [10]. The FOM reached a maximum of $3.86 \times 10^{-2} \Omega^{-1}$ for the electron-irradiated films at $900 \mathrm{eV}$, higher than that of the as-deposited films, which was 1.06 $\times 10^{-2} \Omega^{-1}$. The electron beam irradiation enhances the temperature of ZAS film through energy transfer from the electron beam to the film. This may increase grain size and decrease the sheet resistance (increase the carrier density) of the film [11].

Figure 5 shows a plot of $(\alpha h v)^{2}$ of the ZAS films as a function of the photon energy. The optical absorption coefficient $(\alpha)$ can be calculated from the following Eq. (3) [12]:

$$
\alpha=(1 / t) \ln (1 / T)
$$




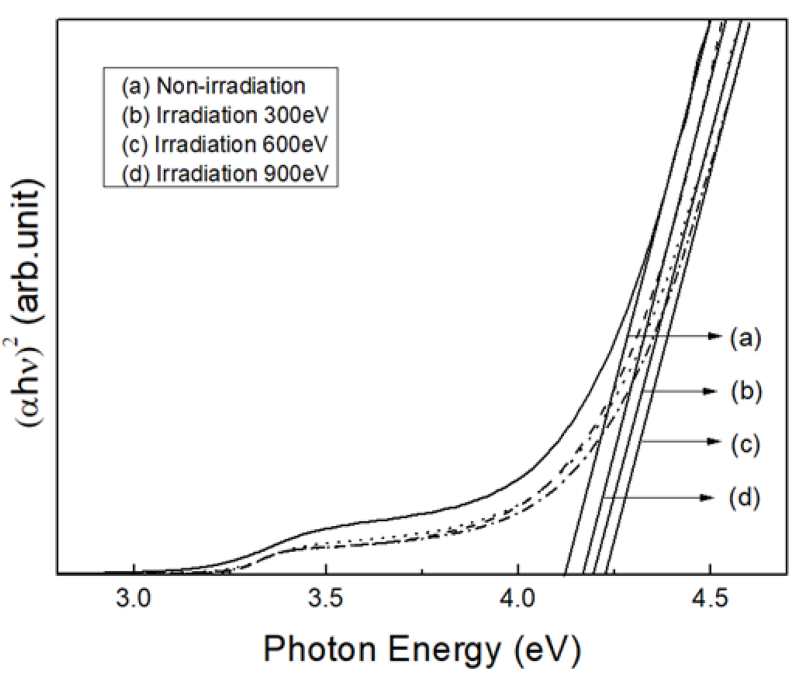

Fig. 5. Plots of $(\alpha h v)^{2}$ as a function of the incident photon energy(hv) for ZAS tri-layer films electron irradiated at different energy. The extrapolation of the linear region to $h v=0$ to determine optical band gap $\left(\mathrm{E}_{\mathrm{g}}\right)$ values is as indicated with lines.

Table 3. The carrier density and optical band gap of ZAS films as a function of electron irradiation energy.

\begin{tabular}{ccc}
\hline $\begin{array}{c}\text { Electron energy } \\
(\mathrm{eV})\end{array}$ & $\begin{array}{c}\text { Carrier density } \\
\left(\times 10^{21} \mathrm{~cm}^{-3}\right)\end{array}$ & $\begin{array}{c}\text { Optical band gap } \\
(\mathrm{eV})\end{array}$ \\
\hline As deposition & 7.1 & 4.12 \\
\hline 300 & 8.3 & 4.19 \\
\hline 600 & 8.6 & 4.23 \\
\hline 900 & 8.2 & 4.16 \\
\hline
\end{tabular}

where $\mathrm{t}$ is the film thickness, and $\mathrm{T}$ is the visible transmittance. The Tauc formula of Eq. (4) gives the relationship between the optical absorption coefficient $(\alpha)$ and optical band gap $\left(\mathrm{E}_{\mathrm{g}}\right)[13]$ :

$$
(\alpha h v)^{2}=A\left(h v-E_{g}\right)
$$

where $h v$ is the energy of the incident photon, and $A$ is the absorption edge width parameter. Figure 4 shows that as the electron energy increases to $600 \mathrm{eV}$, the optical band gap increases proportionally from 4.12 (as deposition) to $4.23 \mathrm{eV}$ (at $600 \mathrm{eV}$ ). Table 3 shows the carrier density and optical band gap of the ZAS films as a function of electron irradiation energy. From the observed electrical properties and optical band gap, it can be concluded that the optical band gap shift is related to the carrier density of the films [14]. The band gap increased from 4.12 to $4.23 \mathrm{eV}$, with the carrier density increasing from 7.1 to $8.6 \times 10^{21} \mathrm{~cm}^{-3}$.
However, the film that was electron irradiated at $900 \mathrm{eV}$ showed a decreased band gap energy of $4.16 \mathrm{eV}$, due to the decrease in carrier density of $8.2 \times 10^{21} \mathrm{~cm}^{-3}$.

\section{CONCLUSIONS}

We deposited conductive and transparent $\mathrm{ZnO} 50 \mathrm{~nm} / \mathrm{Ag}$ $10 \mathrm{~nm} / \mathrm{SnO}_{2} 50 \mathrm{~nm}$ tri-layer films onto glass substrates using $\mathrm{RF}$ and DC magnetron sputtering, and then exposed them to electron irradiation to investigate the effects of electron irradiation on the optical and electrical properties of the films.

In the XRD pattern and AFM images, the crystallite size was observed to increase with electron irradiation energy, and the films electron-irradiated at $900 \mathrm{eV}$ showed the lowest RMS roughness of $1.30 \mathrm{~nm}$. Due to the flat surface and enhanced crystallinity, the ZAS films electron-irradiated at 900 $\mathrm{eV}$ showed a maximum FOM of $3.86 \times 10^{-2} \Omega^{-1}$, which was higher than that of the as-deposited films $\left(1.06 \times 10^{-2} \Omega^{-1}\right)$.

Thus, we conclude that the electron beam irradiation effectively improves the optical and electrical performances of ZAS thin films.

\section{REFERENCES}

1. S. B. Koo, C. M. Lee, S. J. Kwon, J. M. Jeon, J. Y. Hur, and H. K. Lee, Met. Mater. Int. 25, 117 (2019).

2. H. S. Kim and S. J. Kim, Korean J. Met. Mater. 57, 84 (2019).

3. C. S. Huang and C. C. Liu, Microelectron. Eng. 148, 59 (2015).

4. B. B. Sahu, L. Wen, S. H. Kim, and J. G. Han, Vacuum $\mathbf{1 6 5}$ 246 (2019).

5. K. P. Sibin, G. Srinivas, H. D. Shashikala, A. Dey, N. Sridhara, A. K. Sharma, and H. C. Barshilia, Sol. Energy Mater. Sol. Cells 172, 277 (2017).

6. L. Kinner, M. Bauch, R. A. Wibowo, G. Ligorio, E. J. W. List-Kratochvil, and T. Dimopoulos, Mater. Des. 168, 107663 (2019).

7. R. L. Orimi and M. Maghouli, Optik 127, 263 (2016).

8. T. K. Gong, S. B. Heo, and D. Kim, Ceram. Int. 42, 12341 (2016).

9. H. N. Cui, V. Teixeira, L. J. Meng, R. Martins, and E. Fortunato, Vacuum 82, 1507 (2008).

10. G. Haacke, J. Appl. Phys. 47, 4086 (1976). 
11. T. Omata, H. Fujiwara, S. O. Y. Matsuo, N. Ono, and H. 13. J. Tauc, Amorphous and Liquid Semiconductors, Plenum, Ikawa, Jpn. J. Appl. Phys. 37, 879 (1998). New York (1974).

12. S. Peng, T. Yao, Y. Yang, K. Zhang, J. Jiang, K. Jin, G. Li, X. Cao, G. Xu, and Y. Wang, Physica B 503, 111 (2016).

14. Y. Wang, W. Tang, L. Zhang, and J. Zhao, Thin Solid Films 565, 62 (2014). 